\title{
CAMINOS Y ESBOZOS PARA UNA APERTURA FENOMENOLÓGICA DEL HORIZONTE MISMIDAD DESDE LA CONSTITUCIÓN DEL MUNDO EN SER Y TIEMPO DE HEIDEGGER ${ }^{1}$
}

\author{
Juan José Garrido Periñán ${ }^{2}$
}

Resumen: El objetivo principal del artículo es terminar quién es el Dasein desde el aparecer del mundo en la obra de Martin Heidegger Ser y tiempo (\$\$ 14-18). Para ello, se plantea la posibilidad de aprehensión del horizonte del sí mismo del Dasein, en contra de los propios análisis heideggerianos sobre el uno ( $\$ \$ 25-27)$, y, también, se muestra de qué manera la mismidad del Dasein se presupone ya en el modo de aparición del mundo-entorno a través del existenciario significatividad. La conclusión del artículo intentará descubrir los posibles rendimientos fenomenológicos de la apertura del horizonte del sí-mismo del Dasein.

Palabras-clave: Fenomenología; Útil; Dasein; Mundo; Mismidad

\section{INTRODUCCIÓN}

Sin entrar en consideraciones de erudición y establecimiento doxográfico en la obra de Martin Heidegger, este artículo de investigación, a modo de meditación filosófica, tiene un propósito muy concreto: plantear la posibilidad de una aprehensión fenomenológica del horizonte del sí mismo del Dasein, desde las consideraciones fenomenológicas vertidas en una parte de la obra Ser y tiempo

\footnotetext{
${ }^{1}$ Este trabajo se ha realizado bajo la cobertura del siguiente Proyecto I+D De Excelencia: "Dinámicas del cuidado y lo inquietante. Figuras de lo inquietante en el debate fenomenológico contemporáneo y las posibilidades de una orientación filosófica. Configuración teórica y metodológica” (FFI2017/83770-P), financiado por el Ministerio de Innovación, Ciencias y Universidades del Reino de España.

2 Profesor Sustituto Interino en la Universidad de Sevilla, Departamento de Estética e Historia de la Filosofía, Sevilla - España. (1) https://orcid.org/0000-0002-7586-7579 E-mail: jjgarper@us.es Línea de investigación centrada en la obra de Martin Heidegger y sus posibilidades en torno al desarrollo de una fenomenología del sí-mismo.
}

http://doi.org/10.1590/0101-3173.2020.v43esp.20.p269

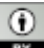

This is an open-access article distributed under the terms of the Creative Commons Attribution License. 
(\$\$ 14-18), donde se establece la constatación del existenciario ${ }^{3}$ [Existenziall] "mundo" como momento estructural del denominado "ser-en-el-mundo" [inder-Welt-sein]. Como es bien sabido, ser-en-el-mundo es una expresión que, para Heidegger, sintetiza la condición formal del Dasein en tanto ente que "se comporta" [sich-verhalten] no solo ante un "mundo circundante" [Um-Welt], sino ante los otros y, sobre todo, con respecto a "sí-mismo" ${ }^{4}$ [Selbstheit]. La hipótesis que se postula en esta meditación apunta a desvelar la "significatividad" [Bedeutsamkeit], que vertebra una parte de la concepción heideggeriana del existenciario "mundo" [Welt], como mecanismo para poder consolidar la pregunta por el "sí-mismo" del Dasein, formulada fragmentariamente en los $\$ \$ 25-27$, cuando queda establecida negativamente, por cuanto se definió como el "uno-mismo"s [man-selbst], y de un modo bastante abstracto-formal, en las derivaciones en torno a la "impropiedad/propiedad"6 [Uneigentlichkeit)

\footnotetext{
${ }^{3}$ Los existenciarios son modos en los que se realiza la existencia, guisas o maneras a través de la cuales el acto de existir se lleva a cabo. Desde la óptima heideggeriana, los existenciarios están en clara oposición con respecto a la quiddidad de lo que "es", lo que, por tradición, fue el modo predominante de determinar el ser del ente, basada en la determinación de una esencia. Estos existenciarios, como se comprenderá en adelante, cumplen una función metódica primordial, pues permiten la no "cosificación", dentro de la dinámica del análisis existencial, de los indicadores que vertebran la existencia.

${ }^{4} \mathrm{El}$ sí-mismo, o la mismidad, apunta a un fenómeno temporal en las dimensiones prácticas del mundo entorno, mundo compartido y, por último, mundo de sí mismo (HEIDEGGER, 2006, p. 176; 1995, p. $11,13,103,187-188,192,204,211,212-214,227-228,228,232,237-241,245-247,253-255$, $298,331-332$; 1992 , p. 54-58, 54-58, 342, 348, 440-441, 442; 1988, p. 29 y 102; 1976, 236, $338-$ $344,344-347$ y 1975 , p. 194, 224-228, 242, 249, 394-395 422, 425). No hay que olvidar que la Analítica Existencial, propedéutica para alcanzar el horizonte de aprehensión de la "Temporalidad del ser" [Temporalität], pasaba, si y solo si, por un análisis de las estructuras existenciales del ente que se pregunta por el ser, el Dasein. No voy a atender en demasía, dentro de los contornos de esta meditación, a esta ligazón del sí-mismo con la temporalidad para su propia mostración fenomenológica.

${ }^{5}$ Baste nombrar la articulación del das Man en la obra heideggeriana y la siguiente afirmación (HEIDEGGER, 2002, p. 271): "Perdido en la opinión pública del uno y en su habladuría, el Dasein, al escuchar al uno-mismo, pasa por alto su propio sí-mismo". [Sich verlierend in die Öffentlichkeit des Man und sein Gerede überhört es im Hören auf das Man-selbst das eigene Selbst]. Las traducciones al espańol de la obra de Heidegger quedan asumidas por mí, aunque las traducciones de José Gaos y Jorge Eduardo Rivera, además de asistir y facilitar la tarea, se han tenido en cuenta. Cuando se considere menester, a fin de ganar una claridad semántica y lingüística, junto a la traducción española, se acompañará el original alemán.
}

6 Se entiende por abstracto, en algún sentido, le necesidad metodológica que obliga a Heidegger a rehuir de formulaciones esencialistas, nucleadas en un contenido quidditativo, no lo que sería el modo de proceder de la actitud teorética. Impropiedad y propiedad, en virtud de su constitución como indicadores formales, son momentos temporales-ejecutivos del modo de ser (existir) denominado Dasein, que, a su vez y "en cada caso" [jeweiligkeit], soy yo mismo. De cualquier modo, Ser y tiempo no postula, para extender el análisis de tales indicadores formales, un horizonte de aquello que sería la "mismidad" del Dasein, a partir de las posibilidades de existencia impropia/propia de este mismo Dasein. Las razones de tal imposibilidad, quizás, se deban a la escrupulosidad metodológica de Heidegger, al no querer entrar en consideraciones antropológicas que "sustancializaran" aquello que es el Dasein: un 
Eigentlichkeit] del existir. No va a ser competencia de este escrito, por tanto, asentar qué sea propio o impropio, sino descubrir los posibles rendimientos, a partir del análisis del mundo como elemento central del modo de ser del Dasein, de la apertura del horizonte del sí-mismo. El hilo conductor que, además, guiará mis pesquisas, tiene una justificación metodológica, la cual, es considerada importantísima: no hay conocimiento explícito y temático de lo más propio, y peculiar, del Dasein, si antes no queda abierto el horizonte del "mundo-entorno" [ $U m$-Welt $]$, en el que éste queda remitido en el imperar, casi absoluto, de toda acción cotidiana. Si de verdad hay que tomar en serio las consideraciones metodológicas compartidas por Heidegger en su opus magnum, no se puede obviar la relevancia de la esfera circunmundana para comprender quién es el Dasein ${ }^{8}$.

Por lo general, el interés de concentrar mi actividad filosófica en el análisis del mundo, como elemento estructural del ser-en-el-mundo, responde, en primer lugar, a un criterio metodológico: el proceder fenomenológicoexistencial nos interpela y hace que partamos del modo cotidiano de existir; en segundo lugar, según parece, el ser más propio, el sí-mismo, solamente puede llegar a ser desvelado como elemento de "modificación" [Verwandlung] de eso que soy mientras estoy absorbido por el fluir constante de la cotidianidad (HEIDEGGER, 2002, p. 271). Por si esto fuerra poco, la intención de seleccionar unos fragmentos, entre tantos, va de suyo acompañado por la pregnancia que conlleva abrir un horizonte ontológico-existencial: la necesidad de poner límites a lo aprehendido. El limite viene marcado por el mero existenciario "mundo" [Welt] y será acompasado por el proceder de la fenomenología, una fenomenología inspirada en la metodología del mismo Heidegger, pero, análogamente, muy preocupada por pensar los fenómenos desde el mismo ámbito de manifestación de su aparecer.

En definitiva, se va a tratar de pensar Ser y tiempo desde su propio modo de aparecer, esto es, sin importar vicisitudes biográficas, de estilo, incluso

ente arrojado en su poder-ser, pero que, del mismo modo y con la misma necesidad ontológica, debe soportar aquello que es, su existencia. Para una respuesta a esta intención de alejamiento ante discursos antropológicos (HEIDEGGER, 1976, p. 313-364).

7 Usaremos, para decir lo mismo, "mundo-entorno" y "circunmundo", en la traducción de Um-Welt.

${ }^{8}$ Como se verá, el proceder fenomenológico-hermenéutico de Heidegger pensará que los modos de tenencia de la vida del Dasein, esto es, los nexos-vitales y las "referencias" [Zusammenhängen] mundanas son mostradores, e indicativos, del proceso de "ejecución" [Vollzug] de la misma existencia. De este modo, desvelando las referencias, es decir, el cómo de la vida, la vida, o la existencia, se hace a sí misma. La "ocupación práctica" [Umgang] es un modo de esta ejecución. 
programáticas, en tanto libro inacabado ${ }^{9}$, para, desde el modo a través del cual Heidegger aprendió la "indicación formal" ${ }^{10}$ [formale Anzeige] llamada mundo, plantear la pregunta sobre el sí-mismo del Dasein, pregunta que es considerada para nosotros vital, a fin de responder a una demanda que, in nuce, es específica de toda analítica existencial: ¿quién es el Dasein? ¿Quiénes somos realmente nosotros?

\section{LA NECESIDAD DE IMPLANTACIÓN DEL PROCEDER FENOMENOLÓGICO: LA FENOMENOLOGÍA PARA UN CORRECTO PUNTO DE ACCESO A LA CUESTIÓN}

¿Por qué tendría la fenomenología una cierta legitimidad para abordar el problema del acceso al mundo por parte del existente llamado humano? ¿Acaso la historia, la medicina, la sociología, la química, la física, etc., no han pensado sobre el mundo, y el ser humano, con suficiente pertinencia y claridad? ¿Estas ciencias, en su proceder científico, de orientación hipotéticomatemática o inductiva-experimental, no ejercen su praxis científica desde alguna que otra concepción de mundo? ${ }^{\text {11 }}$

Sea como fuere, en el orden práctico, lo que hoy se consideran como "ciencias" operan, obteniendo resultados específicos y concretos, sin la necesidad de un replanteamiento de la cuestión del mundo y, ni mucho menos, tienen a la fenomenología como fundamento metodológico de su actividad científica. No necesitan de la fenomenología porque la ciencia ${ }^{12}$ se ha adueñado ya de un acceso al mundo, del conocimiento y hasta del ser humano.

9 Grosso modo, la meta del Tratado era la elaboración de un horizonte temporal, re-obtenido por mor de una hermenéutica de la "temporalidad" [Zeitlichkeit] mundana del Dasein, que sirviera como un "trascendental" desde el que comprender el ser del ente en general, en tanto temporalidad [Temporalität]. Este horizonte trascendental y temporal iba a ser expuesto en la III Sección que no ha sido publicada jamás, por mucho que se considere el curso del Semestre de verano de 1927 su continuación (HEIDEGGER, 1989).

${ }^{10}$ Véase las notas: 3 y 6 . La indicación formal, en la obra del joven Heidegger, son como un prefacio para con los existenciarios (HEIDEGGER, 1995, p. 16).

${ }^{11}$ El problema de la legitimidad de la ciencia en relación con la concepción de mundo fue explorado por Heidegger en un curso de 1919 intitulado: "Semestre por necesidades de guerra" [Kriegnotsemester] (HEIDEGGER, 1999, p. 13-120).

${ }^{12}$ Desde 1919 Heidegger piensa que la filosofía se ejerce dentro de un dominio "pre-teorético" [Vortheoretische], en cuanto actividad que intenta aprehender la experiencia inmediata de la vida, y que queda conformada como "ciencia originaria de la vida" [Urwissenschaft des Lebens]. Por tanto, la filosofía, siendo pre-teorética, tiene como finalidad poner al descubierto las estructuras ontológicas de la vida fáctica, distinguiéndose, en su actividad, de actitudes teoréticas, basadas en la objetivación y la reflexión, como de una actitud de corte práctico, basada exclusivamente en la acción (HEIDEGGER, 1999, p. 13-120). 
Esto indica, por decirlo así, que lo que realza la fenomenología, en tanto saber disciplinado y filosófico, es un retroceso - no un progreso -, el cual vendría atestiguado, necesariamente, por la imposibilidad misma del saber científico, en su vocación de ser mathesis universalis, por determinar objetivamente ${ }^{13}$ los ámbitos de realidad que estamos tratando aquí: "mundo" [Welt], "existencia" [Dasein] y "sí-mismo" [Selbstheit]. Objetivar es, desde Kant (1956), "poner" [setzen] o dotar de quiddidad a lo que es (HEIDEGGER, 1991, p. 13-19, $65-85,171-203$ y 249-312). Por supuesto que, para un moderno, como en el caso de Kant, la actividad relativa al poner es un rendimiento de una instancia subjetiva-trascendental, pero eso no importa a fin de enfatizar el gesto esencial: la realidad es una actividad que se "pone-ahí" y que, por tanto y de alguna manera, se "construye". La realidad es lo construido, conformado por la actividad, en este caso con Kant, del movimiento trascendental. Ahora bien, desde esta concepción epistemológica, mundo, existencia y mismidad, componen una triada que se resiste a la operatividad del poner-ahí, en la medida en que todo intento por definirlas bajo un "es", un qué-es, resulta en un fracaso estrepitoso. Aquí es donde entra el proceder fenomenológico de inspiración heideggeriana: el fracaso viene motivado por una ceguera a la hora de aprehender de qué modo se dan estas daciones, o sea: mundo, existencia y mismidad. Ellas tres no acontecen conceptualmente, en tanto qué-es, sino en la modalidad del "cómo" [Wie]. Aparecen como "maneras de existir" [Weisen $z u$ existieren], que quedan remitidas a un horizonte a priori por el momento ignoto $^{14}$. La fenomenología, si es verdad el dictum husserliano de " $j$ a las cosas mismas!" [zu Sachen selbst.], consiste en la preocupación rigurosa por captar el

${ }^{13}$ Gegenstand es unas de las traducciones al español de objeto, el cual puede ser traducido, del mismo modo, por Objekt. Desde diferentes perspectivas hay quienes sostienen su tajante división (CAYGILL, 2000, p. 317), considerándola importantísima para la matriz filosófica de la filosofía trascendental kantiana, siendo Gegenstände objetos de la experiencia en su sentido lato, mientras que Objekt es el objeto de la experiencia en un sentido restringido, o sea, como objeto relativo al entendimiento. Ahora bien, como digo, hay controversia, Pedro Ribas, uno de los traductores al espańol de la Crítica de la razón pura (KANT, 2005, p. XXV), según parece, desestima la diferenciación, al pensarla de poco importante; también lo hacen Förster y Rosen (KANT, 1993, p. 49), traductores al inglés del Opus Postumun kantiano. Heidegger, a mi parecer, a lo largo de su interpretación, mantiene tal división, entendida en términos ontológicos, en virtud, precisamente, del aporte que lo trascendental tendría sobre la misma experiencia, haciéndola depender de criterios logicistas, es decir, pensado el objeto como Objekt, o correlato lógico de la unidad de apercepción, en presunto divorcio con la intuición sensible, a la que estaría, irremediablemente, emparentada la noción germana Gegenstand.

${ }^{14}$ Este elemento "apriórico" es mentado por Heidegger en tanto horizonte "pre-teorético" [Vortheoretische]. La estructura de "previedad": "haber-previo" [Vor-habe], "ver-previo" [Vor-sicht] y "preconcepción" [Vorgriff], fue desarrollada especialmente en el curso de 1923 (1988). La dilucidación de esta estructura previa es el objetivo final de toda hermenéutica de la facticidad en su aspiración por lograr una situación hermenéutica. 
modo cómo las cosas aparecen, y, por tanto, no se trata, en ningún momento, de imponer o presuponer lo que se da, o sea, aquello que "es", sino, antes bien, partiendo de la manera de aparecer del ente, entrever su génesis trascendental, su estructura a priori, o, con Heidegger, su indicación formal.

El nexo que permite la dilucidación del a priori fenomenológico es establecido, en Ser y Tiempo, a través de la palabra "significatividad" [Bedeutsamkeit]. Significatividad es todo aquello "por-mor-del" [Worumwillen] Dasein. En cierta manera, a priori y significatividad vienen a decir lo mismo: sentido o contexto de "previedad"15. El elemento de sentido, como nexo estructural que argamasa las múltiples significaciones, tanto del ente intramundano, como para con las (auto)referencias existenciales propias del Dasein, es la significatividad. Se puede decir de otro modo, en reserva del dictum fenomenológico: la significatividad es el elemento articulador que permite que lo que se dé, lo haga transido por algo que el Dasein es - que somos en calidad de existentes -. En virtud del hecho de que lo que aparece viene marcado por la significatividad, por algo que somos, en "cada caso"16 [Jeweiligkeit] nosotros mismos, es posible ejercer la tarea trascendental sobre los rendimientos fenomenológicos en tanto estructuras universales, entiéndase, para todo ente-Dasein.

La fenomenología, en resumen, no consiste, tan solo, en erigirse en una actitud respetuosa para con lo que se da, o aparece, sino que intenta desentrañar las condiciones formales-trascendentales que hacen posible todo aparecer. Para Heidegger, el fondo trascendental queda marcado por la "temporalidad del ser" $^{\prime 17}$ [Temporalität $]$. Pero este es otro problema.

${ }^{15} \mathrm{Al}$ mentar la expresión "sentido" se quiere significar, a la par, el horizonte de previedad desde-dónde el Dasein, siendo en el mundo, abre los propios respectos que conforma los útiles en sus "para-algo" [Um-zu]. Resulta conveniente no pensar el sentido como un añadido, a posteriori, de lo articulado como mundo. Tampoco debería ser pensado tal "sentido" como una instancia de carácter subjetivo.

${ }^{16}$ Término no empleado en Ser y Tiempo, al ser reemplazado por Jemeinigkeit. En este caso, jeweilig se traduce por "en cada caso", "cada vez", en virtud de la raíz alemana -weile, esto es, "instante", "momento". He analizado la relación de este concepto en la obra de Heidegger en: (GARRIDO-PERINÁAN, 2017a, p. 533-556), al socaire del concepto paulino de parousia. La relación, además, de jeweiligkeit con el concepto griego kairos es evidente, por cuanto manifiesta el carácter temporal de la existencia, que es propia, si y solo si, en el momento oportuno de una apropiación, proyectada como modificación del estado cotidiano, el existente consigue anteponerse a su tendencial posibilidad a la caída.

${ }^{17} \mathrm{Al}$ contrario que el Prof. José Eduardo Rivera, que traduce "temporalidad” por Temporalität y "temporeidad" por Zeitlichkeit, prefiero no atender a tal división, pues, en cualquier caso, ambos fenómenos, desde el plano de la obra cumbre heideggeriana, vienen a manifestar algo casi idéntico, sobre todo, si me ciño a una de las hipótesis vertidas en el libro de 1927: el Dasein es el ente que trasluce y transparenta, de algún modo, el darse mismo del ser. No hay darse del ser si no pasa por el 


\section{DASEIN “=” Mundo. Los ÁMbitos FenOMEnológicos Del SER-EN Y EL COMPORTARSE}

Una ecuación de igualdad recorre las páginas de Ser y Tiempo: "Dasein = Mundo": "Y si el mundo mismo es un constitutivum del Dasein, la elaboración conceptual del fenómeno del mundo exige una visión de las estructuras fundamentales del Dasein" (HEIDEGGER, 2002, p. 52) ${ }^{18}$. Prima facie, esta igualdad mienta que tanto Dasein como mundo son co-originarios en su mostración, de tal modo que no es posible pensar el uno con independencia del otro. En términos más latos, la igualdad ${ }^{19}$ entre Dasein y mundo determina que el Dasein es lo que hace, a saber, en un primer momento, ante una primera pregunta sobre quién soy, tendría que contestar: soy lo que hago mientras cocino, busco el parque Güell de Barcelona, o quedo absorto viendo un partido de fútbol ${ }^{20}$. Ante esta tesitura, cualquier conocimiento de identidad yoica se debería constituir como un estado de excepción de la inmediatez de la vivencia y, como se sabe, Heidegger no está dispuesto a aceptarlo en honor de la propia fenomenología ${ }^{21}$. Pero lo importante, como trasfondo de la cooriginariedad entre Dasein y mundo, es que, desde una percepción cotidiana, en la expresión: "soy lo que hago", permanecen implícitos los horizontes de comprensibilidad que posibilitan la relación "Dasein = mundo", o mejor: esta relación de co-originariedad ha sido ya planteada y abierta en la "ocupación práctica" [Umgang] relativa a la cotidianidad de todo existente. De lo contrario, la ocupación práctica sería acéfala, carecería de significatividad. Tal

Dasein. Por tanto, ambos conceptos deben entenderse como horizontes de tiempo, esto es, en tanto temporalidad. Lo que sucede es que la palabra Temporalität tiene una finalidad trascendental, pues de lo que se trata es de ganar el horizonte general de presentación del ser del ente. Pero, que no olvide, este horizonte general, de presentación del ser del ente mismo, es la existencia, esto es, el Dasein.

${ }^{18}$ Und wenn Welt selbst ein Konstitutivum des Daseins ist, verlangt die begriffiche Ausarbeitung des Weltphänomens eine Einsicht in die Grundstrukturen des Daseins.

${ }^{19}$ El uso que se realiza sobre el término "igualdad" es retórico, pues Heidegger, desde la concepción de la verdad vertida en Ser y tiempo (HEIDEGGER, 2002, \$44), va a dejar muy claro que la verdad, lo verdadero y el ser-verdadero, como fenómenos relativos a la propia "verdad de la existencia" [Wahrheit der Existenz], no estarán basados en la adaequatio intellectus et rei. Adecuación (adaequatio) e igualdad (aequatio) vienen a manifestar un mismo ámbito de realidad: la correspondencia del entendimiento con la cosa. Siendo, entonces, la verdad la igualdad entre lo pensado y la cosa. Para una ampliación del problema de la verdad y su interpretación aleteiológica (VIGO, 2007, p. 117-142).

${ }^{20}$ (HEIDEGGER, 2002, p. 239): "Se es lo que se hace (practica)" [Man ist das, was man betreibt].

A partir de tan escueta afirmación, se puede comprender el compromiso adoptado, en términos fenomenológicos, con el análisis del mundo-entorno.

${ }^{21}$ Tal afirmación corresponde a la máxima fenomenológica de atenerse al modo en el que se dan las cosas (al cómo) y a su acción derivativa: la "atestiguación” [Bezeugung] de lo dado. 
pregnancia de lo ya abierto por el mundo, a través de la ocupación práctica, fue mentado con Heidegger (2002, p. 15-19), aunque en relación con el sentido del ser, mediante el rótulo de "pre-ontológicamente no extraño" 22 . Para que algo no nos resulte extraño, de algún modo, aunque no temático ni explícito en cuanto tal, tiene que ser (re)conocido, en la medida en que ha de quedar vinculado con el modo de ser del agente práctico, en este caso: el Dasein. No lo olvidemos, el mundo, como se verá más adelante, no es definido como totalidad de entes, sino como un modo de ser del Dasein denominado "mundaneidad"23 [Weltlichkeit]. Mundaneidad no es más que un modo de ser, por la sencilla razón de que no es un ente, una cosa que pueda "ponerse(contra)ahí" [Gegenstand], como sí, en cambio, puede suceder con una mesa o una silla. La mundaneidad apunta a desvelar el carácter ontológico del mundo, o sea, del Dasein, haciendo énfasis en la definición de mundo como proyección horizontal a priori de sentido capaz de contener toda significación particular, así como articular hermenéuticamente todo hacer práctico ${ }^{24}$.

Como ya se puede ir comprendiendo, la fórmula "Dasein = Mundo" no quiere explicitar que el Dasein es su mundo, aunque Heidegger innumerables veces imaginara al existente como un mera "relucencia" [Reluzenz] del mundo en el que habita (2002, p. 175 s.) ${ }^{25}$; más bien, tal expresión de igualdad viene

${ }^{22}$ Esta es una de las tesis metodológicas más importantes del libro, pues va a establecer, a nivel de la comprensión referencial-ejecutiva del Dasein, tres niveles de acceso en el "comportarse" [sich-Verhalten] que es el Dasein mismo: "lo más cercano" [am nächsten], "lo más lejano" [an fernsten] y, por último, "no extraño" [nicht fremd]. La no-extrańeza significa que el Dasein, en cada caso, se relaciona con las cosas bajo el carácter de una pre-comprensión que como, in nuce, está soportando toda aprehensión significativa. Del mismo modo, la posibilidad de que el Dasein, con respecto a sí, no sea del todo extraño va a vertebrar parte de las consideraciones sobre la propiedad/impropiedad (HEIDEGGER, 2002 , $\$ 45-53)$ del existir, determinando la definición del estado de propiedad en tanto "modificación" derivada del modo de ser impropio, no al revés (GARRIDO-PERIÑÁN, 2017b, p. 159-182).

${ }^{23}$ (HEIDEGGER, 1979, p. 228): "por mundaneidad no se entiende el carácter de ser de lo ente, sino el carácter de ser del Dasein y solo a través de él también el de lo ente”.

${ }^{24}$ La noción de mundo, al menos en el opus magnum heideggeriano, es prolija y polisémica, dando lugar a diversas interpretaciones sobre los comentaristas: TUGENDHAT (1970, p. 273-313), quien manifiesta que el concepto de mundo, implícito en el análisis de la angustia, fricciona con el expuesto en el $\$ 18$ de Ser y Tiempo; o FIGAL (2013), a su vez, se muestra contrario a Tugendhat. También son valiosas, a fin de esclarecer tal polisemia, las consideraciones de: KALARIPAMBIL (1999, p. 260) y POCAI (2001, p. 51-67 y 1996, p. 75).

${ }^{25}$ Para extender la temática conviene pensar el existenciario "caída" [Verfallen] y todas sus modulaciones dentro de las "categorías de movimiento" [Bewegungskategorien] de la vida fáctica (HEIDEGGER, 2005, p. 354 ss., y 1985, p. 117-130 y 131-151). Para completar la interpretación: KISIEL (1995, p. 257 ss.) y SEGURA-PERAITA (2002, p. 146 ss.). 
a decir que el Dasein es "ser-en"26 [In-sein]. Pero, a contracorriente, ¿qué tiene que ver lo formulado, en tanto ser-en, con la expresión de equivalencia "Dasein = Mundo"? ¿No es esto una abstracción?

Es sabido que el ser-en constituye un existenciario fundamental a la hora de explicitar el grado de mostración de otro existenciario: ser-en-el-mundo. El seren es un momento estructural del ser-en-el-mundo. De suerte que, ahora, aquello que abre el ser-en recobre vitalidad e importancia, precisamente, de cara a poder aprehender lo que la ecuación "Dasein = Mundo" deja ver: no hay, primero, un mundo o un existente que pueda establecer, como causalmente, en tanto primer principio o comienzo, la relación que comporta tal expresión, sino que la relación es originaria con respecto a sus relatas. El Dasein es una relación abierta inercialmente, y siempre, referida a significaciones que no son elegidas por él, pues son propias de su facticidad, esto es, del "haber-llegado-a-ser" [Gewordensein] (HEIDEGGER, 1995 , p. 67-160). Por tanto, aquello que el “=” implicaba era la constitución cooriginaria de una relación del Dasein con el mundo, transparentando su modo de aparición primaria, como ente emparentado con este mismo mundo, desde aquello que hace o ejerce en su praxis.

Entretanto, la expresión "soy lo que hago" buscaba ganar un ámbito para la mostración del ser-en, estructural en el Dasein, ya que permitía un acercamiento de cara a la obtención de una captación fenomenológica sobre este ser-en entendido como "comportarse" [sich-verhalten], o relación intencional analizable, en tanto modo de ser, por mor de sus referencias hermenéuticas, situacionales y ejecutivas ${ }^{27}$. Ahora, además de recobrar sentido la expresión "soy lo que hago", es menester fijarse en esta otra: "soy mi circunstancia". Solo tiene circunstancia aquel que es una relación co-originaria con sus relatas. De nuevo: el Dasein.

${ }^{26}$ He desarrollado una fenomenología del ser-en, ora acercándome al tema de la "corporalidad" [Leiblichkeit], ora, desde criterios metodológicos a la hora de interpretar la obra Ser y Tiempo, en las siguientes meditaciones (GARRIDO-PERINÁN, 2017c, p. 139-160 y 2017d, p. 63-73). Conviene, empero, destacar que el ser-en, como experiencia fenomenológico-existencial, no ha de mentar el quedar "junto-a/dentro-de" [bei] algo (HEIDEGGER, 2002, p.123-125).

${ }^{27}$ Heidegger propone que las posibilidades de acceso al fenómeno están marcadas bajo tres sentidos: "sentido de contenido" [Gehaltsinn], "sentido de relación" [Bezugssinn] y "sentido de ejecución" [Vollzugssin], siendo el sentido de contenido subsidiario del sentido relacional, esto es, de la forma cómo la existencia es vivida, bajo sus referencias y situaciones concretas y fácticas. El sentido de ejecución es importante aquí porque no hay ningún sentido relacional que no conlleve, desde sí mismo, una ejecución, una praxis, un hacer. Los contenidos que, como indicadores formales expresa la hermenéutica de la facticidad, deben ser, en "cada caso" [jeweiligkeit] ejecutados, llevados a praxis. Esta división, en la manera de entender el fenómeno, no es nueva de Ser y Tiempo, sino que ya fue tematizada, al menos implícitamente en cursos docentes anteriores a 1927 (HEIDEGGER, 1979a, p. 194 ss.). 


\section{SOY MI CIRCUNSTANCIA: DEL CARÁCTER ONTOLÓGICO DEL -UM A LA PREPARACIÓN POR LA PREGUNTA POR EL QUIÉN DEL DASEIN}

La pregunta directriz de esta meditación es aquella que le concierne atestiguar quién es el Dasein, entendido en su conversión fenomenológica: ¿cómo un ente como el Dasein, que no tiene la constitución de un ente intramundano ${ }^{28}$, aparece, si, antes bien, su ser es ser-en, es decir, una relación en apertura y franquía con el mundo en el que vive o habita? ¿Cómo se puede discernir, entonces, lo que soy de lo que el mundo es? Bien es verdad que, si el proceder fenomenológico adoptado al principio no me hubiese alertado sobre las consecuencias que implican partir de la quiddidad del ente, podría haber comenzado mi tarea atendiendo a la concepción del Dasein como animal rationale, o como género albergado en la humanitas y, desde este cobijo, adelantar una definición sobre quién es el existente. Pero no ha sido así, la mirada fenomenológica me alertó, dejando claro que, en un primer momento, si se atiende a lo que hay, a lo que se da, jamás es dado un existente fuera del mundo (HEIDEGGER, 2002, p. 85-133). Tener mundo es tener circunstancias si y solo si la circunstancia es comprendida como elemento contextual que, de algún modo, soporte la significación de aquello que es (existe), y que, por otro, sirva para generar familiaridad para con aquello que relaciona, en este caso: el mundo, comprendido como trama que soporta la relación práctica, no "objetivante", con el entorno (circunstancias). A partir de estas ocupaciones prácticas, en sus efectos colaterales, a la hora de generar ámbitos de pertenencia - o sea circunstancias - es por lo que se constituye el habitar. Siendo preciso, esta es la primera definición que otorga Heidegger sobre el modo de aparecer del Dasein: este es un ente que, nunca estando “junto-a/dentro-del” [bei] mundo, lo habita. Si se prefiere, antropológicamente hablando, el Dasein es un ente habitador de mundo que queda definido, y por tanto englobado, como en cobijo, por el carácter envolvente del -Um, el circum, donde son retenidas todas las posibilidades de pre-comprensión mundana ${ }^{29}$, las cuales, actúan como "suelo fundante" [gründende Boden] para

${ }^{28}$ Vorhandensein se contrapone al modo de ser del Dasein, basado en la existencia, en cuanto "estado de arrojado" [Geworfenheit], que sostiene la propia asunción de su temporalidad, un modo de ser basado en la "cuestionabilidad" de su propio ser. La existencia pertenece al Dasein; el "estar-ahî" a los entes ya dados, en "estado de efectividad" [Wirklichkeit], en la realidad. Por tanto, los entes que no son Dasein, los entes intramundanos, no existen, pues no preguntan sobre sí mismos, no se comportan, asumiéndose, desde un horizonte temporal.

${ }^{29}$ No en vano este ser-en-la-circunstancia, auspiciado por una tarea de orden práctico, le pertenece un tipo de saber denominado "circunspección" [Umsicht]. Es sabido que el vocablo Umsicht es traducido por el joven Heidegger, durante su interpretación de Aristóteles, con el término phronesis, en tanto 
cualquier otro tipo de comprensión epistemológica, incluso para la propia de la ciencia teorética. Habitar es consolidar una pertenencia con lo que rodea siempre a través del ejercicio práctico de ocupaciones que embargan a diario al existente. Empero, en mi opinión, es vital aclarar que el sentido de pertenencia, ligazón, característico de la acción habitar, no viene ejercido por la misma actividad ocupacional y práctica ejercida por el existente, sino, más bien, - y esto es una cuestión metodológica muy importante - la consolidación con el circum es previa y fundante, pertenece al orden del haber-sido del Dasein, a su facticidad. De ahí que el análisis heideggeriano apunte a un esfuerzo denodado de transparencia sobre el fenómeno del "mundo-entorno" [UmWelt] y no, por el contrario, por la dilucidación de la misma acción, entendida como capacidad volitiva del ente-Dasein (prevención de una postura subjetivista). Ahora bien, ¿por qué ha de tener privilegio fenomenológicoexistencial el ámbito de realidad que denota la palabra mundo para un auto-esclarecimiento del modo de aparecer del Dasein? Esta es una pregunta que, llegado a este punto, es necesario responder. La respuesta ya ha sido implícitamente mencionada a lo largo de las páginas precedentes, por cuanto se pensó la co-originariedad de Dasein y mundo, aunque, mientras tanto, no ha sido manifestada explícitamente, ya que, en este nivel de análisis, deudor de la cotidianidad, la expresión Dasein es una palabra aparentemente huera y vacía, casi abstracta, si no viene acompañada del carácter envolvente, soporte del sentido hermenéutico, que comporta el $-U m$. Por esta razón, la pregunta directriz por el quién es el Dasein apunta al esclarecimiento exhaustivo del modo de constitución de la circunstancia, encinta y soportadora de sentido: el mundo. Desde una concepción vaga y mediana, pero no por ello carente de visión $^{30}$, la dimensión que aglutina el "ante-qué" [Wovor] de la circunstancia es el mundo. Heidegger piensa que, si hace accesible el modo de aparecer del mundo, podrá responder a la cuestión sobre quién es el Dasein, en tanto das Man, o sea, como tendencia fáctico-existencial a la caída (HEIDEGGER, 2002, p. 134-149). De suerte para el mismo análisis existencial del Dasein que, tal respuesta, sea incluso insuficiente para con la misma metodología fenomenológica a seguir, la cual nos insta a pensar que, de alguna manera, el Dasein mismo tiene que aparecer, como sí-mismo, en el momento estructural

saber relativo a la circunstancia, cuya finalidad es llevar a buen término la acción humana, siempre orientada y englobada en y desde circunstancias (HEIDEGGER, 2005, p. 115, 376, 384 s; 2002, p. $165-183$ y $193 ; 1992$, p. 22, 47 y 51).

${ }^{30}$ La doxa, como el das Man, aunque son horizontes que limitan una comprensión total, íntegra y ontológica del Dasein, a la par, son fenómenos positivos, en la manera en la que abren una comprensión de aquello que nos rodea. 
del mundo. ¿No es verdad que el existencial que recorre la movilidad formal del Dasein es el ser-en-el-mundo? ¿Qué ha de mentar el existenciario ser-enel-mundo si no es la necesidad perentoria de una existencia de constituirse por y sobre la circunstancia que le rodea? Se puede decir de otro modo: si el Dasein mismo no apareciera ya en la experiencia mediana de ser-en-elmundo, es decir, a través de la habladuría, la curiosidad y la ambigüedad (HEIDEGGER, 2002, p. 185-198), ¿no es cierto que tendríamos que "presuponer" [voraussetzen] el modo de ser del ente llamado Dasein? ¿Qué ha de mentar la palabra "se da" [es gibt] si no es que el ser-en-el-mundo es una intuición experiencial que puede atestiguarse en la misma vida? Es un principio inalienable para la fenomenología, entonces, partir de lo dado, de tal manera que la forma de ser del Dasein - no idéntica ni reducible al modo del "estarahí-efectivo" [Vorhandensein] - tiene que aparecer de algún modo dentro del momento estructural mundo. Esta es mi premisa.

\section{EL EXISTENCIARIO MUNDO: ÚTILES Y SIGNIFICATIVIDAD. UN CAMINO PARA EL PLANTEAMIENTO DE LA MISMIDAD DEL DASEIN}

El existenciario mundo tiene una peculiaridad definida por su tendencia a la ambigüedad. Por un lado, lo que sea mundo, en el análisis existencial llevado a cabo por Heidegger, presenta el carácter de los entes que no son Dasein; por otro, soporta e integra el modo de ser del Dasein, principalmente basado en la significatividad. Las cuatro definiciones de mundo dadas por Heidegger, a saber: uno, el mundo es la totalidad de los entes intramundanos; dos, mundo es, más bien, el carácter de ser del ente intramundano; tres, en tanto fenómeno relativo al Dasein, el mundo es "adonde" este habita; y cuatro, el mundo es el ámbito de acogida y "aprehensibilidad" que soporta a todo ente bajo el formato de la significatividad (HEIDEGGER, 2002, p. 63-113). Pues bien, según se colige de lo expresado, la definición tercera va a ser la que le va a servir de hilo conductor para culminar la tarea de poner al descubierto el mundo como momento estructural del ser-en-el-mundo. Hacer esto, como ya se ha manifestado justo en el punto anterior, significa comenzar desde el habitar, pero siempre en tanto se quiera dilucidar la misma estructura ontológica que soporta tal habitar: el -Um. A partir de entonces, lo que nos encontramos en Ser y tiempo es con una tarea ardua y exhaustiva que tiene como fin transparentar el modo de aparecer del "útil” [Zeug] como elemento 
que, de cierta manera, preconiza la experiencia del mundo entendido en tanto "mundaneidad"31 [Weltlichkeit].

\subsection{El MUNDO Y EL ÚtIL: LA NECESIDAD DE ESCLARECIMIENTO DE LA PREGUNTA POR EL DASEIN}

Quería plantear, desde el análisis del mundo, la pregunta que preparara un acceso, sin contar explícitamente con la deriva del das Man en la que conduce el análisis de Heidegger, a la "mismidad" [Selbstheit] del Dasein. Es, empero, una obligación al menos y, grosso modo, para esta meditación, construir un cuestionamiento que pida cuentas sobre cómo se constituye la experiencia del útil, pues el útil es el nexo que conecta el propio uso particular del ente en cuestión, con la experiencia englobante que, según Heidegger, contiene lo que el mismo útil es. Es de sobra conocido, por lo demás, el estudio que ejerce Heidegger sobre la "condición respectiva"32 [Bewadtnis]. Su proceder es hasta simple, aunque pareciera que su análisis fuera producto de un proceso abstracto y esquivo. Se parte del uso mismo, concreto y particular, a saber, el útil-cuchillo, el cual queda remitido a sus aplicaciones prácticasoperativas, sean las que sean, hasta cortar un trozo de pan como apuñalar. Luego, su uso queda derivado a un horizonte global, holístico y contextual, denominado "contexto pragmático" [Zeugzusammenhang] e incluso "totalidad respeccional"33 [Bewandtnisganzheit]. El momento estructural, que liga

${ }^{31}$ Desde un momento estructural del análisis de Ser y Tiempo, sobre todo en aquel relativo a la aparición del mundo, tanto la mundaneidad como la significatividad pudieran ser fenómenos análogos. Es cierto que la significatividad será el fenómeno que englobe, y, por tanto, acoja al carácter ontológico del mundo - esto es: la mundaneidad -, pues la significatividad mienta estructura de "previedad", donde se configura y adquiere formato todos los fenómenos existenciales, en tanto fenómenos ligados a un horizonte de mundo. Pronto se comprenderá por qué la mundaneidad y la significatividad están hermanadas en un mismo punto: son fenómenos de anticipación que constituyen el soporte a priori de toda experiencia de mundo y, del mismo modo, son fenómenos relativos en exclusividad al modo de ser del Dasein. Una mesa no comporta significatividad, sino el Dasein. Para una aclaración de la expresión mundaneidad, conviene revisar el uso que hace Heidegger del neologismo "mundear" [welten] (HEIDEGGER, 1999, p. 110). Conviene no olvidar las influencias de Emil Lask sobre Heidegger y el llamado por éste: "Principio de determinación material de la forma" (LASK, 1923).

32 Aunque no es nuevo de Ser y Tiempo, pues, desde 1915, Heidegger ya se vale del sentido técnico de respectus como el "enfrente" que soporta la vivencia del yo (HEIDEGGER, 1978, p. 223). La relación con ese horizonte trans-lógico del que versaba Emil Lask son de nuevo evidentes (CROWELL, 2001, p. 101 ss.).

${ }^{33}$ No se quiere expresar que, ambos fenómenos, dentro del análisis heideggeriano, sean idénticos. Antes al contrario, el "contexto pragmático" queda emparentado con el ámbito que soporta el "paraalgo" [Um-zu] de la remisión del útil, mientras la "totalidad respeccional" es un fenómeno ligado al "por-mor-de" [Worum-willen] Dasein, o sea, al ámbito de auto-remisión que todo útil, en tanto paraalgo, comporta. El existenciario del cual es deudor la "totalidad respeccional" es el "todo respeccional" 
la experiencia del útil con el modo de ser del Dasein, es llamado "mundoentorno" [Um-welt], culpable de configurar toda experiencia del Dasein con su mundo y, por tanto, con el útil en su uso particular. El mundo-entorno cumple con la función de estructura de previedad con respecto a la experiencia particular de uso.

¿Cuál es la diferencia, entonces, entre conjunto de remisiones instrumentales propuestas en la totalidad-respeccional y el mundo-entorno? $¿$ No es el mundo-entorno, al igual que la totalidad-respeccional, un contexto holístico e integral que funda la experiencia ocupacional particular? Ante estas preguntas solo cabe responder: sí y no. Sí, son lo mismo en la medida en que ambos existenciarios denotan la necesidad de circunscribir la experiencia del útil, concreta, aquí y ahora, a un horizonte de previedad que engloba, a causa de su permeabilidad hermenéutica, toda significación. Pero no, por cuanto, desde lo extraído del conjunto de remisiones instrumentales, solo tenemos la percepción de que el útil es útil siempre en relación con un para-algo, careciendo del nexo fenomenológico que nos ponga ante la dilucidación de en qué medida el útil dice algo que el Dasein es. La red hermenéutica que conjuga a todos los "respectos" (respectus), en su relación para con los para-algo, a saber, el cuchillo para cortar, tiene que toparse con un límite, pues, de lo contrario, esta cadena, en sus diversos usos, sería ad infinitum. Hay un para-algo que no remite a otro para-algo, que no está en relación con otro respectus: el para-algo en relación con el Dasein, o sea, según Heidegger (2002, p. 86): el "por-morde" [Worum-willen]:

En la comprensión del contexto-referencial ya expresado, desde un poderser asumido en forma explícita o implícita, en forma propia o impropia, por mor del cual él mismo es, el Dasein ya se ha remitido a sí mismo hacia un para-algo ${ }^{34}$.

Aquí radica la importancia del mundo-entorno: conecta la posibilidad de dilucidación de la génesis fenomenológica del útil y, al mismo tiempo, la hace entrar en relación con aquello que el Dasein es. Solo así es posible la afirmación de que "soy mi circunstancia". Resulta cognoscible ser mi

[Bezugsganze], que vendría a actuar de elemento trascendental, por cuanto contendría la totalidad de "condiciones respectivas" [Bewandtnisganzheit] cuanto su (auto)referencia hacia el Dasein - la significatividad y mundaneidad.

${ }^{34}$ Im Verstehen des genannten Bezugszusammenhangs hat sich das Dasein aus einem ausdrücklich oder unausdrücklich ergriffenen, eigentlichen oder uneigentlichen Seinkönnen, worumwillen es selbst ist, an ein Um-zu verwiesen. 
circunstancia solo bajo la condición de que lo que forma y ejerce las circunstancias, las ocupaciones prácticas con los útiles en un mundo, remitan a mí. Ahora bien, ¿qué tiene que ver lo explicitado en este punto con la petición de que la "mismidad" [Selbstheit] del Dasein, desde la experiencia circunmundana, sea mostrada? En mi opinión, mucho, pues lo que afirma Heidegger, ni más ni menos, es que el complejo de fines del para-algo ha de remitir, como suelo fundante, a la experiencia propia, y genuina, del Dasein, a lo que éste es: experiencia de sí mismo. El útil es útil si y solo si remite a la experiencia propia del Dasein, la cual ha de quedar anticipada en la comprensión de aquello que el útil, en su red hermenéutica, de ilación del para-algo, es. Las posibilidades que engloban el modo de ser del Dasein, como ente no conformado por el modo de ser de la presencia o el estar-ahíefectivo, además de solventar el problema del ad infinitum del para-algo, permiten entonces entrever fenomenológicamente el horizonte del sí-mismo o mismidad del Dasein, que, tácitamente, está articulando el modo de aparecer del mundo-entorno. ¿Está ya dado el Dasein en la experiencia del mundoentorno? ¿se puede atestiguar, desde el mundo como momento estructural del ser-en-el-mundo, la posibilidad de aprehensión de la mismidad del Dasein? Por el momento, solo es posible afirmar lo que sigue: si el mundo es aquello que permite el juego de los horizontes prácticos-operativos, donde se resuelven las acciones ocupacionales, el modo de ser de las cosas, etc., el mundo solo es posible, es mundo en cuanto tal, si sus posibilidades quedan ligadas a las posibilidades del Dasein. Todavía no se hecho meridiano, ni siquiera, la forma de la aparición del Dasein como modelo de anticipación comprensiva del útil. Paso a paso.

\subsection{EL MUNDO Y LA SIGNIFICATIVIDAD: LA ANTICIPACIÓN DEL MODO DE SER DEL DASEIN}

Heidegger, llegado aquí, está muy preocupado por mostrar de qué modo la preminencia del "por-mor-de" sobre el "para-(que)" es configuradora de toda intelección y ocupación humana, olvidando, quizás, la necesidad de mostrar el aparecer del sí-mismo del Dasein como fenómeno fundante del darse del mundo: "Este conveniente contexto, que desde la estructura de la condición respectiva conduce al ser del Dasein como el verdadero y único 
por-mor-de, no ha de ser detenidamente profundizada por el momento" (HEIDEGGER, 2002, p. 64) ${ }^{35}$.

Para mi interés, en cambio, esta afirmación solo tiene validez en la medida en que prepara, y permite, el planteo de la pregunta por el sí-mismo del Dasein. El sí-mismo, o mismidad, por el momento, ha quedado vinculado a lo que permite que el contexto holístico, soportador del modo de ser del útil, sea comprendido. Esto es llamado por Heidegger "comprensión de mundo" [Verstehen von Welt] (HEIDEGGER, 2002, p. 86). Estaría muy tentado de manifestar que la comprensión de mundo es equivalente a la comprensión del Dasein, pero decir tal cosa complicaría la transparencia del modo de aparición del propio sí-mismo del Dasein desde la impronta del mundo. En verdad, con Heidegger, no se puede decir que la mismidad se haga temática, directamente, desde la experiencia del útil, pero es que el útil, su intelección, tampoco, ya que toda experiencia utilitaria queda remita a una configuración y apertura previa de sus propios contextos significativos. Resulta muy valioso tener claro que el Dasein no es el instaurador de la apertura previa del ser, sino que se "encuentra" [befindet] con ella. Esta constatación del encuentro se llamará un poco más adelante: "disposición afectiva" [Befindlichkeit] (HEIDEGGER, 2002, p. 134-140), como se sabe, unos de los modos eminentes en las que el Dasein es su "Ahi”" $[D a]$.

Sin embargo, para el interés de esta meditación, conviene centrarse en el fenómeno del mundo, sobre todo porque aquí sale a relucir una referencia fenomenológica sobre el sí-mismo del Dasein. Si el mundo no me pusiera ante un auto-conocimiento sobre mi sí-mismo, no se entendería el análisis que hace Heidegger para con éste. ¿Cómo me pone, pues, el mundo ante mí-mismo? En este sentido, la estructura de previedad, sentido o comprensión de mundo es aquello que el Dasein es: "El en-qué del comprender que se auto-remite, como aquello-con-vistas-a-lo-cual se deja acontecer a los entes en el modo de ser de la condición respectiva, es el fenómeno del mundo" (HEIDEGGER, 2002, p. 86) ${ }^{36}$. Prima facie, esta definición valdría tanto para definir al mundo como al Dasein: ¿no es el Dasein un comprender que, en cada caso, se autoremite y que, por otro, en tanto proyecto-compresor, deja acontecer a todo ente intramundano? La importancia del existenciario mundo recibe aquí su

\footnotetext{
${ }^{35}$ Der angezeigte Zusammenhang, der von der Struktur der Bewandtnis zum Sein des Daseins selbst führt als dem eigentlichen und einzigen Worum-willen, soll fürs erste noch nicht eingehender verfolgt werden. No da más explicaciones sobre la justificación de tal decisión.

${ }^{36}$ Das Worin des sichverweisenden Verstehens als Woraufhin des Begegnenlassens von Seiendem in der Seinsart der Bewandtnis ist das Phänomen der Welt.
} 
preminencia y toda su integridad: el mundo sirve para visualizar el tránsito mundo-Dasein, o sea, desde la dilucidación del existenciario mundo, podemos comprender el hilo conductor de los entes intramundanos hacia el Dasein.

Es el turno, entonces, de explotar el análisis de la relación del mundo con lo que el Dasein es: su auto-referencialidad. Esta determinación, por lo demás, queda remitida a la necesidad de explicitación de las condiciones de posibilidad del mundo mismo, ya que, desde lo abierto por la condición respectiva, es posible explicitar el comportamiento y funcionamiento de los útiles, pero no así preparar la pregunta sobre las condiciones de posibilidad del fenómeno mundo. Estas condiciones de posibilidad radican, no obstante, en el fenómeno de la "significatividad" [Bedeutsamkeit]:

El carácter referencial de estas referencias del remitir nosotros lo concebimos como significar. En la familiariedad con estas referencias, el Dasein significa para sí mismo, se da a entender, originariamente, su ser y poder-ser en relación con su ser-en-el-mundo. El por-mor-de significa un para-algo, éste un para-esto, éste un en lo cual del dejar ser, y éste un con-qué de la condición respectiva. Estas referencias están enganchadas, por debajo de, entre sí, como una totalidad originaria; son lo que son en cuanto son este significar en el que el Dasein se da previamente a entender a sí mismo su ser-en-el-mundo. Al todo-referencial de este significar lo llamamos significatividad (HEIDEGGER, 2002, p. 87)

Nota bene, se puede observar que, en un primer momento, no se habla de significatividad, sino de "significar" 38 [Bedeuten]. El significar es el carácter que conforma todas las remisiones instrumentales, las cuales son englobadas, contextual-holísticamente, solo bajo la condición de ser fenómenos correlativos a la interpretación o comprensión en las que el Dasein, mientras existe, es. ¿Realmente qué tiene que ver tal afirmación con la emergencia del aparecer de la mismidad del Dasein? En mi opinión aquí reside el meollo de la cuestión, por más que, en un primer vistazo, no se pueda obtener una respuesta clara y distinta. Si las remisiones instrumentales, propias de los útiles, son remitidas

\footnotetext{
${ }^{37}$ Den Bezugscharakter dieser Bezüge des Verweisens fassen wir als bedeuten. In der Vertrautheit mit diesen Bezügen "bedeutet " das Dasein ihm selbst, es gibt sich ursprünglich sein Sein und Sein-können zu verstehen hinsichtlich seines In-der-Welt-seins. Das Worumwillen bedeutet ein Um-zu, dieses ein Dazu, dieses ein Wobei des Bewendenlassens, dieses ein Womit der Bewandtnis. Diese Bezüge sind unter sich selbst als ursprüngliche Ganzheit verklammert, sie sind, was sie sind, als dieses Be-deuten, darin das Dasein ihm selbst vorgängig sein In-der-Welt-sein zu verstehen gibt. Das Bezugsganze dieses Bedeutens nennen wir die Bedeutsamkeit.

${ }^{38}$ Bedeuten queda definido por la palabra espańola interpretar, en el sentido de "interpretar" [deuten] en relación con algo.
} 
al significar, esta misma remisión instrumental queda ajustada, y englobada, en tanto condición de posibilidad, al interpretar que el mismo Dasein es un ente sumamente compresor (HEIDEGGER, 2002, p. 142-148). Si esto es atinado, en el análisis fenomenológico llevado a cabo aquí, resulta plausible decir, pues, que el Dasein, su modo de aparecer, ha de quedar ínsito en la propia remisión instrumental. Y, ¿cómo ha de quedar ínsito el Dasein en la referencia instrumental? Repito: "Estas referencias están enganchadas, por debajo de, entre sí, como una totalidad originaria; son lo que son en cuanto son este significar en el que el Dasein se da previamente a entender a sí mismo su ser-en-el-mundo" (HEIDEGGER, 2002, p. 87).

Con lo expresado por Heidegger, no solo se vislumbra la dependencia del para-algo con relación al por-mor-de, sino que sale a luz una de las características idiosincráticas del Dasein: el "anticiparse-a-sí" [Sich-vorwegsein], que será un momento estructural del existenciario total, el "cuidado" 39 [Sorge], pero que aquí ya aparece ligado al mundo, en tanto pre-comprensión, pues, de lo contrario, ¿cuál sería el fundamento fenomenológico-ontológico para atestiguar el sentido que, al parecer, tienen las acciones prácticas humanas en su cotidianidad? Ello es solo posible porque el Dasein anticipa su modo de ser, llamado significatividad, de manera previa y fundante a la acción instrumental, práctica y concreta. Las remisiones instrumentales si y solo si son remisiones instrumentales mientras están conectadas a la comprensión del Dasein, la cual las ha hecho posible bajo la condición de auto-proyección anticipativa de su ser.

La prolijidad del término significar: aquello que permite la remisión, el aparecer del ente mismo y, por último, el por-mor-del Dasein, no debe motivar a un rechazo intelectivo de parte del análisis filosófico llevado a cabo; más bien, se trata de mostrar la posible ambigüedad en la que quedaría el existenciario mundo, por cuanto es el horizonte ${ }^{40}$ que articula las remisiones de los entes intramundanos, en su carácter de útiles, y la propia auto-remisión del ente Dasein, en su significar. Para decirlo ya de manera sintética: la significatividad es la condición de posibilidad que otorga el código a todo tipo de significación

\footnotetext{
39 (HEIDEGGER, 2002, p. 252): "El cuidado es el título ontológico para la totalidad del todo estructural del Dasein". [Sorge ist der ontologische Titel für die Ganzheit des Strukturganzen des Daseins]. ${ }^{40}$ El mundo es un horizonte, por tanto, sirve para determinar el "hacia-dónde", la direccionalidad; por otro lado, horizonte significa horizein, ya que toda dirección limita, abarca; por último, horizonte es la cobertura de la totalidad de entes (HEIDEGGER, 2002, p. 365; 1996, p. 309; 1989, p. 378 y 1979 b, p. 266 y 269).
} 
entre entes intramundanos y la significación que, para sí, el Dasein se da a sí mismo desde la facticidad y su condición arrojada.

\section{LA PREgUNTA POR LA MISMIDAD DEl DASEIN DESDE El MOMENTO ESTRUCTURAL MUNDO: DESARROLLO, TEMATIZACIÓN Y POSIBILIDAD ANTICIPATIVA}

Sin salir del momento estructural del análisis del mundo, ¿cuál sería el modo genuino de aparición del ente Dasein, en tanto ente "en" el mundo, y no como ente "dentro-del mundo", o ente absorbido por la cadente interpretación proporcionada por la caída? ¿He preparado el terreno para responder a tal pregunta? ¿Se me ha mostrado ya un modo de ser del Dasein en el análisis del mundo, del útil y de la comprensión de mundo? Creo que sí. Para responder a tales preguntas es menester dejar claro que no voy a considerar la conclusión heideggeriana sobre la determinación de los existenciarios "para-algo" o "pormor-de" como esquemas temporales determinadores de toda experiencia (HEIDEGGER, 2002, p. 369). No lo hago, empero, por considerarlo errado, sino debido a la razón perentoria de que Heidegger se ve obligado, por los compromisos adquiridos en Ser y Tiempo, a pensar el ser en tanto "temporalidad" [Temporalität], sobre todo si quiere lograr la "trascendentalidad" ontológica que, desde el principio, anhela ${ }^{41}$. La temática de la temporalidad tiene la capacidad de situar el proceder fenomenológico en la ontología, pero, en virtud del carácter general y trascendental que comporta, puede favorecer una cierta pauperización sobre las exigencias fenomenológicas en torno al modo de aparición, desde el análisis del mundo, del sí-mismo del Dasein.

La conclusión del análisis llevado en esta meditación es que, en verdad, desde un sentido primordial, el mundo es un fenómeno que queda condensado en la significatividad. La razón se debía a que toda remisión comporta la significación como fenómeno ontológico y, del mismo modo, todo significar emanaba del característico y peculiar ser del Dasein, desde su manera de estar y de ser una anticipación de carácter auto-proyectivo. Siguiendo este hilo conductor, y como último punto a modo de conclusión, voy a ahondar en tal posicionamiento del Dasein como un significar emanado de una capacidad auto-proyectiva/anticipativa, intentando proporcionar una tesis de lectura, una propuesta propositiva en la que se enmarcaría este ejercicio filosófico llamado meditación. Quizás la significatividad no sea más que un fenómeno

${ }^{41}$ Recomendamos releer la nota 9 para aclarar las razones de la afirmación mentada. 
de la anticipación del modo de ser del Dasein, la cual se anticipa en tanto yasida por la facticidad.

\section{Conclusiones}

Los análisis sobre la anticipación y el "adelantarse a la posibilidad" [Vorlaufen in die Möglichkeit] vienen después en la obra Ser y tiempo (GARRIDO-PERIÑÁN, 2019, p. 175-200).

La razón principal es que Heidegger se ve forzado, en primer lugar, a encontrar un existenciario que sirva de unidad y principio sintetizador de todos los momentos existenciales del Dasein: el cuidado. Todo esto queda justificado si pensamos que Heidegger cree comprender que el ser es tiempo

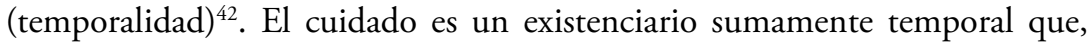
en su constitución, engloba los tres éxtasis temporales: anticipación (futuro), ser-en (presente) y ser-ya-en-medio-de (pasado) ${ }^{43}$. De tal forma que, a partir de entonces, Heidegger puede dar el salto a la II Sección, donde expone un intento, casi circular, de consolidación de la experiencia de la propiedad, lo ontológico, en camino hacia la comprensión mediana, respectiva y en concordancia con el modo de ser del ente intramundano. A resultas de todo, lo que quedaba ya, en la nunca publicada III Sección, era realizar una destrucción de la historia de la ontología con el único fin de preparar la pregunta por el sentido de la "temporalidad del ser" [Temporalität des Seins]. $\mathrm{Y}$ esto lo puede hacer, en concreto, porque Heidegger ha pensado que ya ha atestiguado el momento estructural-unitario del Dasein: el cuidado. Pues bien, a lo largo de esta meditación, he usado el término "sí-mismo" o "mismidad" 44 [Selbstheit] con el objeto de mentar la relación auto-proyectiva del Dasein con su propio modo de ser. Tal relación de ser se ha manifestado en la manera de una anticipación que se desarrolla en relación con la forma de acontecer del ente intramundano llamado útil. En las remisiones instrumentales, e incluso

\footnotetext{
${ }^{42}$ Lo dice claramente (HEIDEGGER, 2002, p. 369): "Solo sobre la base en la temporalidad extáticohorizontal es posible la irrupción del Dasein en el espacio". [Nur auf dem Grunde der ekstatischhorizontalen Zeitlichkeit is der Einbruch des Daseins in den Raum möglich].

${ }^{43}$ Su definición queda establecida tal que así (HEIDEGGER, 2002, p. 192): “el ser del Dasein es un anticiparse-a-sí-estando-ya-en(el-mundo-) en-medio-de (el ente que comparece dentro del mundo). Sigo la traducción del Prof. Jorge Eduardo Rivera (HEIDEGGER, 2016, p. 210).

${ }^{44}$ Las expresiones "sí-mismo" y "mismidad" vienen a traducir la palabra alemana Selbstheit. Me he valido de la significación en tanto "carácter de sí mismo". A lo largo de la meditación, en cada caso, la he usado para indicar un mismo horizonte significativo: la relación que guarda el Dasein con respecto a sí.
} 
en el contexto holístico que las soporta de una manera previa, estaba ya dado el modo de ser del Dasein, un modo de ser basado en la significatividad, palabra que soportaba toda posible significación, otorgándole, por así decir, el código de "aprehensibilidad" para todo usufructo del útil particular y/o ente intramundano. ¿Qué es lo que ha revelado el análisis del mundo para que el Dasein, en tanto sí-mismo, haya salido a la luz? A mi juicio, de manera notoria, la evidencia de que el mundo consiste, en su darse fenomenológico, en una anticipación del agente de experiencia, es decir: del Dasein. Solo de esta manera tiene sentido la articulación misma de los respectos instrumentales: bajo la condición de que estén ligados a las posibilidades de ser del Dasein. Es claro, entonces, la preeminencia del Dasein con respecto al entramado circunspectivo, específico del comercio de los entes intramundanos, en su modalidad de útiles. Sin embargo, como Heidegger está cansado de repetir ${ }^{45}$, tal preeminencia no significa que los útiles son fenómenos que el Dasein pone-ahí, cual actividad de producción, más bien, lo que hay de fondo es un encuentro con algo que ya (se) es, que el Dasein, en cada caso, debe retener y sostener, en tanto movido proyectivamente por la "cuestionabilidad" [Fraglichkeit] de su existir.

¿Qué es lo que ya-(se)-es? La significatividad. Metodológicamente hablando, la significatividad, como fenómeno que guía toda estructura llamada mundo, funciona como un "trascendental", a la manera de impedir la comprensión de los fenómenos en tanto elementos subjetivos del Dasein, pues la genuina articulación del "por-mor-de" [Worum-willen] no pertenece a una capacidad volitiva, racional, consciente, del ente llamado Dasein. Esta es la razón por la que el mundo resulta en un existenciario primario: es el articulador de la cadena de los "para-algo", pero, análogamente, del "por-morde", relativo a la auto-referencialidad del Dasein, su respectivo sí-mismo. Por otro lado, que el encuentro con lo que ya-es venga adjetivado por la palabra significatividad, está puesto en relación con la constatación de que el Dasein se encuentra con posibilidades, no abstractas, sino articuladas ya en un horizonte de mundo (preeminencia de la historicidad).

Por último, considero debidamente mostrado que ya, desde el análisis del mundo como momento estructural del ser-en-el-mundo, aparece la dimensión del sí-mismo del Dasein, entendida como la auto-referencialidad de los fenómenos de los útiles para con el Daseiny, con la misma intensidad, a causa

\footnotetext{
${ }^{45}$ Parte de las anotaciones de los llamados "Cuadernos Negros" [Schwarze Hefte] constituyen una revisión de las derivas de Ser y Tiempo, por lo que la reserva del propio Heidegger hacia los movimientos del idealismo, el subjetivismo o el humanismo, son muy claras. Al respecto, y a modo de señalización (HEIDEGGER, 2014, p. 10, 42, 53, 56, 94 ss.).
} 
de que tal auto-referencialidad a la manera del proyecto, se revelara como una anticipación del Dasein con su propio ser. Auto-referencialidad y anticipación son modos del si-mismo del Dasein, porque son experiencias específicas de este tipo de ente marcado por la existencialidad y la cuestionabilidad. Tiene que quedar claro que, desde el análisis fenomenológico heideggeriano, ser-símismo no tiene nada que ver con que el Dasein logre constituirse como ego cogito o sujeto-trascendental, sino con la - si se quiere así - "evidenciación" de su peculiar modo de ser (GARRIDO-PERIÑÁN, 2018, p. 150-174). A partir de todo esto, se ha de comprender la afirmación de que el Dasein se da para sí mismo en toda actividad práctica, con los útiles y signos, como en su "ser-con" [Mit-sein] (GARRIDO-PERIÑÁN, 2019, p. 175-200). Darse antes a sí mismo significa que el Dasein queda anticipado en la estructura misma de significación que soporta toda relación con los útiles. De ahí que a la espacialidad le corresponda erigirse como posibilidad propicia para la "propiedad" [Eigentlichkeit] y, por tanto, para desvelar un aspecto de la mismidad del Dasein. No es solo el tiempo el trascendental para lograr tal tentativa (GARRIDO-PERIÑÁN, 2018, p. 150-174). Comprendemos, ahora, cuán importante es señalar esta conexión con el sí mismo desde la cotidianidad media del Dasein, en su circunspección, pues, entre tanto, una forma de ser sí mismo, y conocerse, resulta de transparentar cómo estamos en la ocupación, entregados en una circunstancia. Así se gana un ámbito de auto-esclarecimiento de la vicisitud en el hacer práctico, sin necesidad del desvelamiento del cuidado en tanto existenciario que supura nuestra constitución temporal.

Si Heidegger hubiera enfatizado las referencias de lo denominado sí-mismo, desde la ocupación práctica, no solo podría haber abordado el problema de la espacialidad con más amplitud ${ }^{46}$, también hubiera obtenido una suerte de topografía existencial cuya finalidad hubiese sido, precisamente, aquella específica de la hermenéutica de la facticidad: situarnos en el punto de acceso correcto en la "aprehensibilidad" de las cosas. El desvelamiento de la auto-referencialidad y la anticipación desde la emergencia hermenéutica de los útiles ayudaría, sin lugar a duda, a llevarlo a cabo.

\footnotetext{
${ }^{46}$ Hay quien ha abordado la importancia del espacio en la obra de Heidegger (FRANCK, 1986 y SLOTERDIJK, 2011).
} 
PERIÑÁN, J. J. G. Paths and sketches for a phenomenological opening of the horizon selfhood since the constitution of the world in Heidegger's being and time. Trans/form/ ação, Marília, v. 43, p. 269-294, 2020. Edição Especial.

\begin{abstract}
The main goal of the paper is to determine who is the Dasein itself from the appearance of the world in the Book of Martin Heidegger Being and time ( $\$ \$ 14-18)$. For this, it raises the possibility of understanding the horizon of the self of Dasein itself differently to Heidegger's analysis about the they $(\$ \$ 25-27)$ and also it shows how the Selfhood of Dasein is presupposed already in the appearance of the world-environment through the existential meaningfulness. The conclusion of this paper will try to discover the phenomenological yields of Dasein's openness as horizon of its Selfhood.
\end{abstract}

Keywords: Phenomenology. Equipment. Dasein. World. Selfhood.

\title{
REFERENCIAS
}

CAYGILL, H. A Kant dictionary. Oxford-Massachusetts: Blackwell, 2000.

CROWEL, S. Husserl, Heidegger, and the Space of Meaning: Paths toward Trascendental Phenomenology. Illinous: Northwestern University Press, 2001.

FIGAL, G. Martin Heidegger. Phänomenologische der Freiheit. Tübingen: Mohr Siebeck, 2013.

FRANCK, D. Heidegger et le problème de l'espace. Paris: Éditions de Minuit 1986.

GARRIDO-PERIÑÁN, J.J. La pregunta por el quién del ser-con: Heidegger en su Ser y Tiempo. Anales del Seminario de Historia de la Filosofía 36 (1), p. 175-200, 2019.

GARRIDO-PERIÑÁN, J.J. Horizontes fenomenológicos de la espacialidad en Ser y Tiempo: la relevancia del ser-en como vía de acceso a la mismidad del Dasein. Eidos: Revista de Filosofía de la Universidad del Norte 29, p. 150-174, 2018.

GARRIDO-PERIŃÁN, J.J. La experiencia de la religiosidad: caminos fenomenológicos en busca de la mismidad del Dasein. Heidegger y la fenomenología de la religión. Revista Portuguesa de Filosofía 73, p. 533-556, 2017.

GARRIDO-PERIÑÁN, J.J. En busca del sí mismo perdido del Dasein: un diálogo entre Kafka y Heidegger en torno a la cuestión de la culpabilidad y la mismidad. Endoxa: Series Filósoficas 40, p. 159-182, 2017.

GARRIDO-PERIÑÁN, J.J. Fenomenología del ser-en: ciencia originaria de la vida y hábitat del Dasein. En búsqueda de la vivencia inmediata de la vida. Revista da Faculdade de Letras da Universidade do Porto 33, p. 139-160, 2017. 
GARRIDO-PERIÑÁN, J.J. Ser-en-el-cuerpo: tentativas para un esclarecimiento sobre cómo aparece un cuerpo. En y mundo. Daimon: Revista Internacional de Filosofía. Suplemento 5, p. 63-73, 2017.

HEIDEGGER, M. Schwarze Hefte: Überlegungen II-VI (1931-1938), IV. Abteilung, Band 94, Frankfurt a. M.: Vittorio Klostermann, 2014.

HEIDEGGER, M. Einführung in die phänomenologische Forschung. II. Abteilung, Band 17, Frankfurt a. M.: Vittorio Klostermann, 2006

HEIDEGGER, M. Ser y Tiempo. Madrid: Trotta, 2006.

HEIDEGGER, M. Phänomenologische Interpretation ausgewählter Abhandlungen des Aristoteles zu Ontologie und Logik. Gesamtausgabe, II. Abteilung, Band 62, Frankfurt a. M.: Vittorio Klostermann, 2005.

HEIDEGGER, M. Sein und Zeit. Tübingen: Max Niemeyer, 2002.

HEIDEGGER, M. Die Idee der Philosophie und das Weltanschauungsproblem (Kriegsnotsemester 1919), en: Zur Bestimmung der Philosophie, II. Abteilung, Band 56/57, Frankfurt a. M.: Vittorio Klostermann, p. 13-120, 1999.

HEIDEGGER, M. Einleitung in die Philosophie, II. Abteilung, Band 27, Frankfurt a. M.: Vittorio Klostremann, 1996.

HEIDEGGER, M. Phänomenologie des Religiösen Lebens. II. Abteilung, Band 60, Frankfurt a. M.: Vittorio Klostermann. 1995.

HEIDEGGER, M. Platon: Sophistes. II. Abteilung, Band 19, Frankfurt a. M.: Vittorio Klostermann, 1992.

HEIDEGGER, M. Kant und das Probleme der Metaphysik, I. Abteilung, Band 3, Frankfurt a. M.: Vittorio Klostermann, 1991.

HEIDEGGER, M. Die Grundprobleme der Phänomenologie, II. Abteilung, Band 24, Frankfurt a. M.: Vittorio Klostermann, 1989.

HEIDEGGER, M. Ontologie (Hermeneutik der Factizität), II. Abteilung, Band 63, Frankfurt a. M.: Vittorio Klostermann, 1988.

HEIDEGGER, M. Phänomenologische Interpretationen zu Aristoteles. Einführung in die phänomenologische Forschung. II. Abteilung, Band 61, Frankfurt a. M.:

Vittorio Klostermann, 1985,

HEIDEGGER, M. Prolegomena zur Geschichte des Zeitbegriffs. II. Abteilung, Band 20, Frankfurt a. M.: Vittorio Klostermann, 1979a.

HEIDEGGER, M. Metaphysische Anfangsgründe der Logik im Ausgang von

Leibniz, II. Abteilung, Band 26, Frankfurt a. M.:Vittorio Klostermann, $1979 \mathrm{~b}$.

HEIDEGGER, M. Frühe Schriften 1912-1916, I. Abteilung, Band 1, Frankfurt a. M.: Vittorio Klostermann, 1978. 
HEIDEGGER, M. Wegmarken. Gesamtausgabe, I. Abteilung, Band 9, Frankfurt a. M.: Vittorio Klostermann, 1976.

HEIDEGGER, M. Der Grundprobleme der Phänomenologie, II. Abteilung, Band 24, Frankfurt a. M.: Vittorio Klostermann, 1975.

KANT, I. Crítica de la razón pura. Trad. Pedro Ribas. Madrid: Taurus, 2005.

KANT, I. Opus postumun. Trads. E. Förster y M. Rosen. New York: Cambridge University Press, 1993.

KANT, I. Kritik der reinen Vernunft. Hamburg: Felix Meiner Verlag, 1956.

KALARIPARAMBIL, T. Das befindliche Verstehen und die Seinsfrage. Berlin: Duncker \& Humblot, 1999.

KISIEL, Th. The Genesis of Heidegger Being and Time. California: University of California Press, 1995.

LASK, E. Die Logik der Philosophie und die Kategorienlehre. En: Gesammelte Schriften II, Tübingen: J. C. B. Mohr, 1923.

POCAI, R. Die Weltlichkeit der Welt und ihre abgedrängte Faktizität. En: Th.

Rentsch (ed.), Martin Heidegger. Sein und Zeit. Berlin: Academia Verlag, p. 51-67. 2001.

POCAI, R. Heideggers Theorie der Befindlichkeit. Sein Denken zwischen 1927 und 1933. Freiburg am Brisgau: Karl Alber, 1996.

SEGURA-PERAITA, C. Hermenéutica de la vida humana. En torno al Informe Natorp de Martin Heidegger. Madrid: Trotta, 2002.

SLOTERDIJK, P. Sin Salvación: tras las huellas de Heidegger. Trad. Joaquín Chamorro. Madrid: Akal, 2011.

TUGENDHAT, E. Der Wahrheitsbegriff bei Husserl und Heidegger. Berlin: W. de Gruyter, 1970.

VIGO, A. Arqueología y aletheiología, y otros estudios heideggerianos. Buenos Aires: Biblos, 2007.

Recebido: 11/9/2017

Aceito: 29/11/2018 
PERIÑÁN, J. J. G. 